\title{
The ethical and legal implications of the Human Tissue Amendment Act 2020 (Vic)
}

Steve Philpot and David Anderson

The Human Tissue Act 1982 (Vic) has recently been amended by the Human Tissue Amendment Act 2020 (Vic). In an effort to better reflect the modern practice of organ donation, the intention of the amendment is to include a process for the authorisation of ante-mortem procedures in patients being considered for organ donation after circulatory determination of death (DCDD). ${ }^{1}$ As part of this process, the amendment introduces a new requirement for consent for such antemortem procedures, and specifies that:

A designated officer for a hospital must not give an authority ... in respect of a person unless, where the respiration or the circulation of the blood of the person is being maintained by artificial means, two registered medical practitioners, neither of whom is the designated officer and each of whom has been for a period of not less than five years a registered medical practitioner, have each certified in writing -

(a) that the practitioner has carried out a clinical examination of the person while the respiration or the circulation of the blood of that person was being maintained by artificial means; and

(b) that, in the practitioner's opinion, at the time of examination, death of the person would occur as a result of the withdrawal of the artificial means of maintaining the respiration or the circulation of the blood of the person. $^{2}$

While seemingly straightforward, this has introduced the potential for moral distress among practitioners delivering end-of-life care in the intensive care unit. Two intensivists are now required to make an entry in the clinical notes stating that, in their professional opinion, the patient will die as a result of the withdrawal of life sustaining treatment (WLST). This has made many intensivists reflect on an ethical principle instilled in us from early in our training that WLST is not a volitional act that results in the death of the patient. Could the new documentation requirements imply that we are in fact causing death?
There are various ways in which health care staff justify WLST. These include differentiating killing a person from allowing them to die of their underlying condition, considering WLST as an act equivalent to withholding treatment, and an argument mostly confined to philosophers, namely that WLST represents a form of justifiable killing. The first two arguments are invalidated by the new requirements of the Human Tissue Act, and we will discuss these in further detail, along with the implications of their rejection.

\section{Killing or letting die?}

Karen Quinlan had a severe hypoxic brain injury following respiratory arrest from a drug overdose in $1975 .{ }^{3}$ Her parents petitioned a local court to have her removed from life-sustaining treatment and were informed that, in the opinion of the court, this would violate New Jersey homicide statutes. Her doctors specifically commented that WLST was not allowed because Quinlan was not brain dead. On appeal, the New Jersey Supreme Court ruled that continuing treatment not thought to be in Quinlan's interests by her surrogate decision makers violated her constitutional right to privacy and thus was not allowable. They also stated that her death "would not be homicide, but rather expiration from existing natural causes". ${ }^{4}$ Quinlan had WLST but continued to breathe. She was transferred to a nursing home where she continued to be fed and hydrated until she died some 9 years later of pneumonia.

Many years later, in Airedale NHS Trust $v$ Bland, ${ }^{5}$ the court determined that it was not lawful to cause or accelerate death, but that it was lawful to withhold life-extending treatment (in that particular case, artificial feeding).

Although commonplace and acceptable now, the practice of WLST in patients with a hopeless prognosis (or any condition that left them fully and continuously dependent on some form of organ support) was once questionable. Quinlan's doctors' concern that they may be charged with murder was, at the time, quite valid. It raises an interesting question though, and one which is relevant to the recent law change in Victoria: when they removed her breathing 


\section{POINT OF VIEW}

tube, were Quinlan's doctors intending to kill her, or were they letting her die?

Killing a person may be defined as intentionally acting to cause the death of that person. Letting someone die, on the other hand, is intentionally refraining from carrying out actions which are likely to prevent their death. In either case, someone is dead and someone else acted, or omitted to act, resulting in their death. The common dogma in medicine is that killing is distinct from (and worse than) letting die. WLST can be considered allowing the patient to die of their underlying disease or injuries, rather than constituting an act of killing.

McGee ${ }^{6}$ argues that legally (in most jurisdictions), WLST is regarded as letting die because the life sustaining treatment was provided in the first place and is now being withdrawn. Put another way, a treatment on which a patient is dependent and from which they cannot safely be liberated is not lifesaving, merely life-extending. So, withdrawal of such treatment only affects the timing of death rather than causing it. This argument is easier to support when there is a lengthy period of time between WLST and death. It could hardly be argued the Quinlan's doctors killed her when they removed her ventilation, as she survived for 9 years. Even still, the argument is still made when death is anticipated to occur very soon after WLST.

The Human Tissue Act amendment invalidates the argument that the person dies as a result of their underlying disease by requiring an opinion that death will occur as a result of WLST. Such a statement can be interpreted as meaning that death is caused by the act of WLST rather than the underlying disease. The Human Tissue Act amendment does not specify that death will occur in a certain timeframe after WLST; however, the very fact that $D C D D$ is being considered presupposes an opinion that death will occur quickly.

\section{Withdrawing or withholding?}

McGee goes on to discuss the well accepted equivalence principle wherein withdrawing a treatment that is no longer beneficial (or in the patient's interests) is morally and legally the same as withholding that treatment. This principle is well known to intensivists and referenced explicitly in the Australian and New Zealand Intensive Care Society Statement on Care and Decision Making at the End of Life. ${ }^{7}$ If we consider WLST to be a temporary cessation of intermittent treatment, followed by the decision to withhold its reintroduction, then the moral equivalence of WLST and withholding treatment is established. This is applicable, for example, to a decision to withhold future episodes of intermittent haemodialysis from a patient with end-stage renal failure. The patient can then be said to have died after withholding treatment, rather than its withdrawal. The argument potentially becomes less compelling when the therapy is of a higher frequency, such as the individual breaths delivered by a ventilator.

The requirements of the Human Tissue Act amendment also invalidate this argument. Documenting an opinion that death would occur as a result of WLST implies that it is WLST itself, rather than its subsequent withholding, that is antecedent to death.

\section{Justifiable killing}

Taking a position that may make many intensivists uncomfortable, Philosopher James Rachels argues that there is no moral distinction between killing and letting die. ${ }^{8}$ He makes this argument with the case of the "nasty cousins", wherein a man who stands to inherit a sum of money drowns his cousin in the bath. Another man, who also stands to inherit a large sum of money and intends to drown his cousin, finds the cousin accidentally drowning and does nothing to prevent his death. In one case the cousin was killed, and in the other the cousin was allowed to die, but there seems to be no moral difference between the cases as in both cases the agent intended the death of his cousin. The act is clearly different, but the moral consequences are the same.

Rachels uses this case to argue that the aforementioned belief in medicine that we are allowing patients to die rather than killing them is flawed. He believes that physicians have created an artificial distinction in order to circumvent the sanctity of life doctrine that medicine has inherited from Catholic ethics. In a similar vein to the cousins, "If a doctor lets a patient die for humane reasons, he is in the same moral position as if he had given the patient a lethal injection for humane reasons". 8

If one agrees with the logic in Rachels' nasty cousins thought experiment, then one cannot help but find that killing and letting die are morally equivalent. Therefore, it should be irrelevant whether Quinlan's doctors (or presentday intensivists) intended one or the other. It can be argued that Quinlan's doctors were intending to kill her, as are all doctors who withdraw mechanical ventilation with the intention that the patient die as a result. It is, after all, clearly an act that leads immediately to a person's death, and the requirements of the Human Tissue Act amendment make this clear. The character of the person carrying out the act and the rationale for the act seem more morally relevant than the act itself or even, to a degree, the consequences.

Acceptance of the notion of "justifiable killing" would solve the ethical concerns raised by the Human Tissue Amendment Act, but create new ethical problems, particularly in cases of potential DCDD donors. In a situation 


\section{POINT OF VIEW}

where there is potential for a perception of a conflict of interest, it is particularly important that health care staff are not seen to be acting to bring about the death of a patient for the benefit of donation. It is far more comfortable to consider the previous two justifications for WLST instead of accepting the notion of justifiable killing, although as argued, these may no longer be tenable.

\section{Conclusion}

So where does this leave the Victorian intensivist wondering what legal liability or moral culpability might ensue from a well intentioned statement of prognosis in a patient's notes? The requirement to write that death will occur as a result of the WLST has understandably caused anguish, and from a legal perspective it has not yet been tested whether writing one's intentions so clearly could create a legal vulnerability. However, it is important to note that, just as intention is important in matters of morality (as highlighted in Rachels' nasty cousins thought experiment), it is also relevant in matters of law. The explanatory memorandum states that the intention of the law is to authorise premortem procedures; that is, to help, not hinder, the intensivist in their care of the dying patient. Clearer wording of the required documentation may have made the law's position (and intention) explicit, and may have assuaged concerns (eg, "in my opinion, withdrawal of the artificial means of maintaining the respiration or the circulation of the blood of the person would allow the person to die from their underlying illness"). Such a statement would be more in keeping with the ethical principles outlined above and accepted in intensive care practice in Australia and New Zealand.

In the meantime, health care staff should continue, as always, to have in mind the wishes, values and interests of the patient. They can be reassured by the fact that the ethics literature provides cogent and compelling arguments in favour of the view that WLST is ethical and does not constitute killing. They can also be reassured of the legality of WLST as governed by the Medical Treatment Planning and Decisions Act 2016 (Vic). ${ }^{9}$ Part 1, section 8 of that Act states that a "(h)ealth practitioner cannot be compelled to provide ... futile or non-beneficial medical treatment". The Act also makes it clear that a person, or their medical treatment decision maker, if they do not have decisionmaking capacity, maintains the right to refuse treatment.

\section{Competing interests}

No relevant disclosures.

\section{Author details}

Steve Philpot $1,2,3,4$

David Anderson $2,4,5$

1 Cabrini Hospital, Melbourne, VIC, Australia.

2 The Alfred, Melbourne, VIC, Australia.

3 Organ and Tissue Authority, Canberra, ACT, Australia.

4 Monash University, Melbourne, VIC, Australia.

5 Ambulance Victoria, Melbourne, VIC, Australia.

Correspondence: sjphilpot@gmail.com

doi: https://doi.org/10.51893/2021.3.POV

\section{References}

1 Human Tissue Amendment Bill 2020 (Vic) Exploratory Memorandum.

2 Human Tissue Amendment Act 2020 (Vic).

3 Re Quinlan (70 NJ 10, 335 A.2d 647 (NJ 1976)).

4 McFadden RD. Karen Ann Quinlan, 31, dies; focus of '76 right to die case. New York Times 1985; 12 June: section A, p 1. https:// www.nytimes.com/1985/06/12/nyregion/karen-ann-quinlan-31dies-focus-of-76-right-to-die-case.html (viewed July 2021).

5 Airedale National Health Service Trust v Bland [1993] AC 789.

6 McGee A. Acting to let someone die. Bioethics 2015; 29: 74-81.

7 Australian and New Zealand Intensive Care Society. ANZICS statement on care and decision-making at the end of life for the critically ill; 1.0 ed. Melbourne: ANZICS, 2014. https:// www.anzics.com.au/wp-content/uploads/2018/08/ANZICSStatement-on-Care-and-Decision-Making-at-the-End-of-Lifefor-the-Critically-III.pdf (viewed July 2021).

8 Rachels J. Active and passive euthanasia. In: Kuhse H, Schüklenk $U$, Singer P; editors. Bioethics: an anthology. Malden MA: John Wiley and Sons, 2016; pp 248-251.

9 Medical Treatment Planning and Decisions Act 2016 (Vic). 